ARTIGO ORIGINAL

\title{
Itinerância, intensificação e condições de trabalho de professores de educação física como condicionante de motivação e bem-estar
}

\author{
The itinerancy, intensification and working circumstances of physical education teachers \\ as a conditioning factor of motivation and well-being
}

\author{
Susana Hahn ${ }^{1}$, Arestides Pereira da Silva Junior ${ }^{1}$, Carlos Seibert ${ }^{2}$, Dartel Ferrari de Lima ${ }^{1}$, Jorge Both ${ }^{1}$, \\ Oldemar Mazzardo ${ }^{1}$, Adelar Aparecido Sampaio ${ }^{1}$ \\ ${ }^{1}$ Universidade Estadual do Oeste do Paraná (Unioeste), Marechal Cândido Rondon, Brasil \\ ${ }^{2}$ Núcleo Regional de Educação/Secretaria da Educação e do Esporte do Paraná (NRE/SEED), Toledo, Brasil
}

\section{HISTÓRICO DO ARTIGO \\ Recebido: 23 junho 2021}

Revisado: 03 outubro 2021

Aprovado: 01 novembro 2021

\section{PALAVRAS-CHAVE:}

Itinerância; Docência;

Educação Física.

\section{KEYWORDS:}

Itinerancy; Teaching; Physical Education.

\section{RESUMO}

INTRODUÇÃO: As crescentes demandas do trabalho docente, a itinerância entre escolas desencadeiam processos de intensificação e precarização da função laboral docente.

OBJETIVO: Analisar situações de itinerância, intensificação e condições de trabalho e suas consequências à motivação, carreira e condições de bem-estar de um grupo de professores de Educação Física de um município do extremo oeste do Estado do Paraná, Brasil.

MÉTODOS: É um estudo qualitativo, de corte transversal e de cunho descritivo desenvolvido com dez professores de Educação Física de escolas públicas estaduais e municipais de um município do extremo oeste do Estado do Paraná. Foram utilizados na coleta de dados um questionário sociodemográfico para caracterização dos participantes e uma entrevista semiestruturada, com roteiro referente às condições laborais e suas relações com itinerância entre escolas e intensificação do trabalho docente. As análises dos resultados foram realizadas com base no plano de análise de conteúdo proposto por Bardin (2011).

RESULTADOS: O estudo levantou dados que evidenciam a motivação para a docência, embora as manifestações de instabilidade de vínculo empregatício, a constante necessidade de itinerância entre escolas e a limitação e fragmentação de suas atribuições profissionais. Tais entraves aparecem como desencadeantes da intensificação, limitação e fragmentação do trabalho docente sendo fator determinante para o estresse excessivo, desajuste no nível de integração com ambiente de trabalho, no modo com que enfrentamento de demandas profissionais e desenvolvimento na carreira.

CONCLUSÃO: A itinerância dos professores entre escolas acentua um quadro de intensificação e precarização do trabalho docente, com potencialidade para impactar em sua motivação e bem-estar docente.

\section{ABSTRACT}

BACKGROUND: The increasing demands of teaching work and itinerancy among schools trigger processes of intensification and precariousness of the teacher working conditions.

OBJECTIVE: To analyze situations of itinerancy, intensification and working conditions and their consequences to the motivation, career development, and welfare of Physical Education teachers from a municipality in the west of Parana State, Brazil.

METHODS: It is a qualitative, cross-sectional, and descriptive study developed with ten physical education teachers from state and municipal public schools. A socio-demographic questionnaire for the characterization of the participants and a semi-structured interview were used in the data collection, with a script referring to the working circumstances, and its relations to itinerancy among schools and intensification of teaching work. The results were analyzed based upon the content analysis plan proposed by Bardin (2011).

RESULTS: The study collected data that evidence the motivation for teaching, despite the manifestations of job instability, the need for travelling among schools and the limitation and fragmentation of their professional attributions. Such obstacles emerge as triggers of the intensification, limitation, and fragmentation of teaching work, being a determining factor for excessive stress, misadjustments in the work environment, in the way of coping with professional demands, and career development.

CONCLUSION: The itinerancy of teachers among schools accentuates the intensification and precariousness of teaching work, with the potential to impact on their motivation and well-being. 


\section{INTRODUÇÃO}

Na maioria dos países, incluindo o Brasil, as instituições educacionais passam por transformações estruturais que insinuam o desenvolvimento de novas adequações metodológicas para atender às mudanças sociais (BELL-RODRíGUEZ; FÉLIX, 2020). Concomitantemente, as instituições educacionais tentam responder, prontamente, às suas preocupações a favor da inclusão e da busca pela equidade no combate a heterogeneidade das condições educacionais ofertadas ao público escolar (KRAWCZYK; VIEIRA, 2006).

As proposições das condições educacionais, muito embora, carreguem consigo um "ideal nobre", colateralmente, podem afetar diretamente o professor, seja no exercício profissional ou em sua vida pessoal, podendo impactar diretamente no seu bem-estar. De fato, o professor, quando confrontado, abruptamente, com as consequências das políticas reformistas do sistema escolar, pode ser exposto a conversão para novos modelos de profissionalismo, dos quais, não foi ou não está preparado para assumir (FERRETTI, 2018).

A década de 1990, marcou um novo processo a respeito das demandas educativas no Brasil, à mudança de paradigma sobre as ações educacionais, o que desencadeou uma série de reformas educacionais (AZEVEDO, 2004; OLIVEIRA, 2004; AZEVEDO; SILVA; ABREU, 2008; SHIROMA, 2011; ABONIZIO, 2012; SAVIANI, 2012; SEKI et al., 2017). Essas mudanças na educação brasileira, contribuem para o crescimento da flexibilização do trabalho docente por meio de formas de contratações precárias com benefícios e salários inferiores, principalmente nas redes públicas de ensino (SILVA, 2017; 2018), e impõe aos professores, a necessidade de confronto cotidianamente com os imprevistos inerentes à sua intervenção e com uma série de exigências, expectativas e contingências que atravessam e influenciam seu trabalho.

Esse cenário, marcado por demandas que frequentemente extrapolam sua atividade laboral, gera como consequências, processos que desencadeiam a precarização do trabalho docente e potencialmente afetam o rendimento e a condição de bem-estar do professor (SAMPAIO; STOBAUS, 2015). Um fenômeno antigo que recentemente tem recebido acompanhamento para maior compreensão, está relacionado com a itinerância do trabalho docente, termo cujo significado descreve o ato de deslocar-se constantemente entre várias escolas para a atividade laboral (BOING, 2008). Como consequência, esse evento apresenta um potencial para a precarização do trabalho docente e consequentemente o agravamento nas condições de saúde do professor, seja no trabalho ou na vida pessoal (BALL et al., 2013).

Há que ressaltar a recorrência dos termos itinerância e professor itinerante que circula na literatura e na legislação educacional, como modalidade de atendimento de Educação Especial, na qual se define como atribuição dos professores itinerantes a assessoria às escolas regulares no atendimento a alunos com necessidades educacionais especiais, integrados em turmas regulares e à produção de materiais pedagógicos necessários para auxiliar a inclusão dos mesmos (PELOSI; NUNES, 2009; SILVA et al., 2020). Como nova configuração, tem sido relacionado na profissão docente de modo mais amplo, como consequência do processo de intensificação e precarização do trabalho docente (MARIN, 2004; MILANI, 2008; PEREZ GOMEZ, 2010; SAMPAIO; RUFINO; BENITES; SOUZA NETO, 2017; KRUG, 2017). Seki et al. (2017) revelam que essa situação, acontece com mais frequência com os professores temporários, uma vez que esses profissionais não possuem um vínculo duradouro com a escola e, geralmente, necessitam trabalhar em mais de uma escola.

No que diz respeito aos professores de Educação Física, as condições de trabalho quase nunca atendem o idealizado pelos docentes, o que pode impactar diretamente na motivação e desenvolvimento pessoal e profissional. Nesse caso, o princípio de causa e efeito parece não ser favorável, com obstáculos que chegam a demonstrar muitas vezes o estado crescente de desinteresse por ser professor de Educação Física, com o desinvestimento na carreira se aproximando cada vez mais do seu início (BOTH; NASCIMENTO, 2010; MAROSTICA; SAMPAIO, 2015; RUFINO; BENITES; SOUZA NETO, 2017).

Ante às limitações de suas condições de trabalho e a intensificação das atividades docentes, inúmeras dificuldades são manifestadas pelos professores, como escassez de tempo para trocar experiências, avaliar suas práticas e articulá-las às ações de outros professores, acúmulo de turmas, sobrecarga de atividades, itinerância entre escolas ou outros ramos de trabalho para suplementação da renda, além do cansaço físico e emocional que produzem consequências para o desenvolvimento profissional (WITTIZORECKI; MOLINA NETO, 2005) e surgem como uma série de dilemas que sedimentam ações de precarização do trabalho dos professores (RUFINO; BENITES; SOUZA NETO, 2017).

Dessa forma, constata-se que ainda carecem estudos que esclareçam as perspectivas acerca dos condicionantes relacionados ao trabalho docente e suas consequências. A partir desse contexto, o objetivo do estudo foi analisar as situações de itinerância, intensificação e condições de trabalho e suas consequências no que tange à motivação e a condição de bem-estar de um grupo de professores de Educação Física de um município do extremo oeste do Estado do Paraná, Brasil.

\section{MÉTODOS}

O estudo foi inspirado em um método de pesquisa qualitativa, de corte transversal e de cunho descritivo que buscou compreender a essência da situação em torno do problema central do estudo (MARCONI; LAKATOS, 2005).

Foram entrevistados dez professores de Educação Física, de ambos os sexos, com regime de trabalho docente em diferentes escolas públicas estaduais e municipais de um município de porte médio (53 mil habitantes) do extremo oeste do Estado do Paraná (IBGE, 2020). Na pesquisa, os professores participantes são identificados como P1 a P10. A faixa etária dos participantes foi de 38 a 50 anos de idade, sendo que $70 \%$ da amostra constituída por professoras. Do conjunto da amostra, $90 \%$ dos participantes eram professores Licenciados ou Licenciados/Bacharéis graduados pela Universidade Estadual do Oeste do Paraná (Unioeste), sendo que $60 \%$ possuíam pós-graduação de nível Lato Sensu e, um participante, Stricto Sensu (mestrado).

O grupo de professores participantes referiram se dedicar 
ao magistério a pelo menos seis anos, variando de 06 a 29 anos de trabalho docente. Metade dos participantes da pesquisa (50\%) referiram carga semanal de trabalho de 40 horas. Todos atuavam na rede pública de ensino, sendo $80 \%$ de professores efetivos. Apenas um professor ( $10 \%$ da amostra) atuava em um único estabelecimento de ensino, os demais, atuavam em até cinco estabelecimentos, com média de quilometragem percorrida por dia no deslocamento entre as escolas de $25 \mathrm{~km}$. A distribuição de cada participante está apresentada na Tabela 1.

Tabela 1. Distribuição do perfil laborativo de professores de Educação Física $(\mathrm{n}=10)$, Oeste do Paraná.

\begin{tabular}{ccccccc}
\hline $\begin{array}{c}\text { Participan- } \\
\text { tes } \\
(\mathbf{n}=\mathbf{1 0})\end{array}$ & $\begin{array}{c}\text { Tempo de } \\
\text { docência } \\
\text { (anos) }\end{array}$ & $\begin{array}{c}\mathrm{C} / \mathrm{H} \\
\text { semanal } \\
\text { (horas) }\end{array}$ & $\begin{array}{c}\text { Tipo de } \\
\text { vínculo }\end{array}$ & $\begin{array}{c}\mathbf{N}^{\circ} \text { de } \\
\text { escolas } \\
\text { que atua }\end{array}$ & $\begin{array}{c}\text { Média de } \\
\text { alunos por } \\
\text { turma }\end{array}$ & $\begin{array}{c}\text { Itinerância } \\
\text { (km/dia) }\end{array}$ \\
\hline $\mathbf{1}$ & 29 & 40 & $\mathrm{E}$ & 04 & 36 & 21 \\
$\mathbf{2}$ & 28 & 30 & $\mathrm{E}$ & 02 & 42 & 8 \\
$\mathbf{3}$ & 19 & 40 & $\mathrm{E}$ & 03 & 30 & 5 \\
$\mathbf{4}$ & 6 & 30 & $\mathrm{~T}$ & 01 & 34 & 36 \\
$\mathbf{5}$ & 10 & 40 & $\mathrm{~T}$ & 02 & 25 & 25 \\
$\mathbf{6}$ & 16 & 40 & $\mathrm{E}$ & 03 & 36 & 56 \\
$\mathbf{7}$ & 25 & 40 & $\mathrm{E}$ & 04 & 35 & 20 \\
$\mathbf{8}$ & 16 & 44 & $\mathrm{E}$ & 05 & 30 & 36 \\
$\mathbf{9}$ & 22 & 44 & $\mathrm{E}$ & 03 & 35 & 10 \\
$\mathbf{1 0}$ & 20 & 20 & $\mathrm{E}$ & 02 & 15 & 30 \\
\hline
\end{tabular}

Nota: $\mathrm{E}$ - Efetivo; T-Temporário.

Fonte: Os autores (2021).

Os professores responderam a uma entrevista semiestruturada, a qual foi guiada a partir de roteiros baseados em estudos previamente publicados, relacionados com a precarização do trabalho docente, na proposta de Sampaio e Marin (2004), Krug (2017), Silva e Guillo (2015). Um questionário sociodemográfico foi utilizado para caracterizar a formação acadêmica e o histórico da trajetória laboral de cada participante. As entrevistas foram conduzidas por um agente previamente treinado e preparado, realizado de forma individual em um local apropriado e com a utilização de um gravador de áudio. A duração média de cada entrevista foi de aproximadamente 30 minutos e foram transcritas em sua íntegra.

As coletas de dados foram realizadas no período entre agosto e outubro de 2019. Ressalta-se que todos os professores assinaram o Termo de Consentimento Livre e Esclarecido para participar da pesquisa que foi aprovada pelo Comitê de Ética em Pesquisa com Seres Humanos da Universidade Estadual do Oeste do Paraná (UNIOESTE), conforme o Parecer no 2.414.959.

A análise dos resultados foi realizada com base no plano de análise de conteúdo proposto por Bardin (2011), obedecendo às seguintes etapas: (a) pré-análise; (b) fase de exploração do material/categorização e; (c) fase de análise dos resultados. Como categorias resultantes da entrevista, foram priorizados alguns indicadores, todos estabelecidos a priori, conforme roteiro de entrevista elaborado a partir dos referenciais de Sampaio e Marin (2004), Krug (2017) e Silva e Guillo (2015), que resultou nas categorias: motivação e desenvolvimento da carreira docente, itinerância na função docente e intensificação do trabalho docente.

\section{RESULTADOS E DISCUSSÃO}

\section{Motivação e desenvolvimento da carreira docente}

A motivação para a carreira docente é essencial para a garantia da qualidade da educação e, para tanto, deve-se levar em consideração tanto aspectos pessoais quanto profissionais dos professores (DAVOGLIO; SPAGNOLO; SANTOS, 2017). Para compor esse indicador, as questões da entrevista estavam ligadas às formas de contratação e motivação para o trabalho, política salarial, perspectivas e esperanças para o desenvolvimento profissional (SAMPAIO; MARIN, 2004; KRUG, 2017).

A motivação para o trabalho estava presente, principalmente na percepção do envolvimento com os alunos em relação à Educação Física. Isso foi evidente nos relatos dos participantes:

Encontro bastante estímulo, justamente pela condição que é a disciplina de Educação Física [...] de ver muitas crianças com vontade de aprender, de ter conhecimento, de buscar por algo (P1);

Me sinto de certa forma motivado porque é algo que eu escolhi fazer (P3);

Eu me sinto supermotivada, é isso mesmo que eu gosto de fazer (P10).

É importante que o docente se sinta motivado em sua profissão em qualquer fase da carreira, pois, assim poderá obter melhor qualidade na transmissão dos seus conhecimentos, bem como, favorecerá a possibilidade de sucesso dos alunos (GUIMARÃES, 2013). Krug, Krug e Conceição (2013), identificaram que a motivação do professor de Educação Física ocorre em qualquer momento da carreira e por diferentes razões, mas destacam o relacionamento com os alunos e o desejo permanente de ser professor como os principais aspectos evidenciados pelos professores participantes da pesquisa.

Os professores relataram que existem entraves que incidem diretamente na motivação com repercussões para o desenvolvimento profissional, como algumas medidas burocráticas que envolvem o desgaste sobre a função docente. Como exemplos, destacamos os seguintes depoimentos:

"[...] a questão de muitas exigências, muita burocracia, isso é mais desgastante do que o trabalho em si junto aos estudantes" (P2);

"O sistema que deveria ser uma forma de simplificar e favorecer o trabalho, ele acaba produzindo o efeito contrário, que é o efeito burocrático de controle do nosso trabalho, então, o que importa é você estar com o sistema atualizado" (P9).

A burocracia, o gerencialismo e o crescente controle do trabalho dos professores atua como influente na motivação e no desenvolvimento profissional, sendo que os procedimentos burocráticos estão, normalmente juntos com a imposição administrativa, que vem acompanhada de um plano de ação, no qual existe pouco espaço de liberdade para criatividade dos docentes (PEREZ GOMES, 2001; FLORES, 2011). Esse processo supõe uma imposição sem sentido que acumula atuações artificiais, saturação de tarefas e responsabilidade profissional, com propósito de cumprir expedientes, com possibilidade de ainda se converter em um instrumento de dominação e controle das minorias divergentes e contestatórias (PEREZ GOMES, 2001).

Nos últimos anos, o docente tem sofrido formas de controle cada vez mais sutis por parte dos órgãos centrais que 
coordenam e dirigem o sistema educacional. Na escola, essa manifestação passa pela maior supervisão, prescrições didáticas-curriculares detalhadas, livros didáticos, novas tecnologias, ampliação de processos avaliativos, que buscam responsabilizar o professor por quase toda situação negativa, expondo claramente ações para disciplinar e controlar sua força de trabalho (OLIVEIRA; VIEIRA, 2012; VIEIRA, 2019).

Para Quadros et al. (2018), os iniciantes na carreira docente, sentem-se muitas vezes à deriva de um sistema administrativo interno escolar e as condições de trabalho oferecidas podem reforçar ainda mais o "choque com a realidade" quando chegam ao "chão da escola" e enfrentam situações de conflitos, não possuem espaço físico adequado para ministrar suas aulas não possuem materiais suficientes, fatores que causam ao professor iniciante um estresse considerável, levando-o ao possível desinvestimento na carreira profissional (QUADROS et al., 2018).

Quando questionados sobre as perspectivas e esperanças do seu desenvolvimento profissional sobre a carreira docente, os professores relatam que o sistema educacional está passando por um momento delicado, devido algumas medidas governamentais. Tal fato se manifesta nos profissionais da educação sentimentos de desvalorização, desânimo, desmotivação, medo, preocupação e insegurança quanto ao futuro profissional:

[...] sobre as medidas governamentais, na verdade assim, é uma insegurança muito grande. Do governo você sabe que vem bomba, vem uma situação, vem políticas novas, você sabe que não vão ser boas [...]. Isso acaba interferindo muito no teu trabalho, na tua realização (P3);

Motivação para o trabalho, eu acho que são poucas, principalmente, porque a gente não tem avanço, não tem reposição salarial e cada vez está pior nas escolas. [...] está fazendo 2 anos que o governo não está dando nem o piso salarial, nem a inflação, está bem complicado isso (P7);

[..] eu já fui mais motivado com a profissão e com o trabalho, mas por várias questões a motivação abaixou bastante. A questão da desvalorização, do salário que nós tivemos uma redução nos últimos anos, as condições de trabalho na nossa área que são bastante precárias (P9).

Sampaio e Marin (2004), destacam que uma das questões bem visíveis da precarização do trabalho do professor refere-se ao salário percebido pelo tempo de dedicação às suas funções, sobretudo quando se focaliza a imensa maioria, ou seja, os que atuam nas diversas escolas da rede pública de ensino. Nascimento et al. (2021), em recente estudo, retratam a remuneração como a única foi a única dimensão a não ser avaliada de forma satisfatória por nenhum dos grupos de professores avaliados, dentre diversas outras dimensões como a autonomia no trabalho, progressão na carreira, integração social, leis e normas do trabalho, relevância social do trabalho.

No mesmo sentido, Ventorim, Astori e Bitencourt (2020) revelam com preocupação que atualmente o Brasil passa por um período de intenso desinvestimento e desmonte pelo governo federal em relação à educação, a desqualificação da profissão, o descaso com a formação continuada de professores, assim como a associação da formação docente às avaliações externas.

Por outro lado, é notório na fala dos professores que a questão da instabilidade de vínculo empregatício surge como componente desmotivador na carreira, como relatam P4 e P8:
[...] quando você é PSS ${ }^{1}$, você pega as aulas, ainda mais quando é substituição, você sabe que não vai ficar muito tempo ali, então, isso geral um desconforto [...] daqui a pouco eu estou desempregada de novo [...] (P4);

Com esse novo modelo de contrato precarizado eu não estou otimista, porque o ser humano precisa de estabilidade, sem estabilidade ele vai carregar sempre as preocupações com e, e ele não vai estar focado no trabalho como deveria estar (P8).

Seki et al. (2017), revelam que quase um milhão de professores no Brasil trabalham na condição de professores temporários e não possuem a certeza da continuidade do seu exercício profissional, o que dificulta o seu planejamento a longo prazo, seja nas questões profissionais e até mesmo pessoais. Quando o professor é efetivo, ou seja, apresenta estabilidade de vínculo trabalhista, este se sente seguro, pois, sabe que seu vínculo de emprego é garantido, como revela P9:

[...] como eu sou concursado, nesse aspecto até me sinto um pouco melhor do que outros colegas, porque eu tenho um plano de carreira (P9).

Conforme Valle (2003), a carreira docente por meio de concurso público, possibilita a efetivação e, consequentemente, a conquista de estabilidade no posto de trabalho, além de conceder status profissional e proteção pelo estatuto de funcionário efetivo nos quadros da administração pública. O professor concursado/efetivo, consente a construção de uma carreira profissional, o que lhe permite projetar os planos para o futuro e evitar o constante enfrentamento das incertezas do mercado de trabalho.

Nas formas de contratação temporária dos professores, se verificam, principalmente, o processo de deterioração do trabalho docente, pois basta realizar uma comparação entre a lei que rege a vida profissional dos professores efetivos e a dos contratados por tempo determinado e seu agravamento ocorre de forma encoberta, uma vez que não se leva em conta a carga horária, salas de aula superlotadas de alunos, salários baixos, condições de trabalho, trabalhos extraclasse como correções de provas e preparação de aulas que ocupam o tempo de lazer, independentemente de o professor ser ou não efetivo (MILANI; FIOD, 2008).

\section{Itinerância na função docente}

A itinerância é entendida neste trabalho como um termo cujo significado está relacionado com o ato do professor que trabalha em várias escolas e que necessita se deslocar constantemente, sem estar num local de forma permanente (BOING, 2008). Outro termo encontrado na literatura para designar o deslocamento contínuo para atendimento do trabalho docente, surge da denominação do aplicativo Uber que popularizou uma forma de contratação no mundo dos transportes individuais, tem se alastrado em alguns países, incluindo o Brasil (POCHMANN, 2016; FONTES, 2017) e tem gerado novos termos, como a 'uberização das relações de trabalho' e o verbo, 'uberizar'" (FONTES, 2017, p. 54). Assim, para a elaboração desta subcategoria, a partir das análises, foram realizadas indagações sobre o número de escolas em que o docente atua como professor de Educação Física e se a rotatividade/itinerância exerce pressão e desgaste na sua vida, já que esse evento desencadeia

'É a sigla utilizada para os professores contratados por "Processo Seletivo Simplificado - PSS" no Estado do Paraná. Os contratos desses docentes são por tempo determinado. 
a intensificação do exercício da docência e influencia na precarização do trabalho docente (BOING, 2008). Portanto, é um fator determinante pelo estresse excessivo, limitação e fragmentação do trabalho docente. Isto fica claro na explanação dos sujeitos investigados, de acordo com as exposições a seguir:

Atualmente eu estou em quatro colégios para esse ano e, que eu percebo que cansa mais é o deslocamento, mas não o trabalho em si (P1);

Atuo em três escolas atualmente então esse é um desgaste muito grande $[. . .]^{\prime \prime}$. [...] é um desgaste físico e mental que acaba interferindo no que você está fazendo. (P3);

Este ano eu estou em três escolas, mas eu já estive em cinco. Com essa rotatividade você não cria um vínculo com a escola e nem com os alunos [...] (P6);

Eu tenho cinco escolas e é muito cansativo. Eu estou chegando agora no mês de outubro, e começo a sentir um cansaço maior do que no início do ano [...] (P8).

O estudo, constatou-se que $90 \%$ dos professores de Educação Física exercem suas funções em mais de uma escola e isso tem consequências, conforme evidenciado nos relatos anteriores e apresentados na literatura. Seki et al. (2017) ressaltam que esse panorama é preocupante, sendo necessário uma política pública que favoreça os processos de formação inicial e continuada de professores, assim como a realização de concursos públicos para a ampliação de vagas para professores efetivos. 0 aumento da carga horária de trabalho e a necessidade de atuar em duas ou mais escolas para suprir necessidades econômicas, pode concorrer para a vivência de condições estressantes nos locais de trabalho o que, consequentemente, interfere negativamente na satisfação no trabalho (NASCIMENTO et al., 2021).

No entanto, é importante destacar que nos resultados dessa pesquisa, $80 \%$ são professores efetivos e apenas $20 \%$ temporários. Além disso, o único professor que atua em apenas uma escola é um professor temporário. Ou seja, essa constatação vai no sentido contrário do que geralmente é encontrado nas escolas, quando professores efetivos tendem a fixar a sua atuação em um número menor de escolas.

No decorrer dos tempos, o processo educativo tem sido alterado conforme as mudanças sociais, políticas e econômicas, com impactos no funcionamento das escolas e na vida docente (WITTIZORECKI, 2009; WITTIZORECKI; MOLINA NETO; BOSSLE, 2012). Nesse cenário, o trabalho do professor de Educação Física, tem sido assinalado por diversas transformações. Na esfera administrativa do Estado do Paraná, a diminuição de escolas, turmas e da carga horária de projetos específicos, tem ocasionado a necessidade de itinerância dos professores por várias escolas durante o ano letivo.

A itinerância, conforme dados levantados no estudo, acarreta na intensificação do trabalho docente para poder atender as demandas de cada escola (reuniões, formações específicas, atividades com a comunidade e coletivo docente); dificuldade para manter o equilíbrio entre vida pessoal e profissional; redução de tempo para repouso entre turnos de trabalho; e, cansaço pelo intenso trânsito entre as escolas. É perceptível na fala do P9, a falta de vinculação estável em determinada escola, mesmo com a experiência profissional. Tal fato, favorece limitações de possibilidades de exercício profissional em um contexto de forma contínua, como expõe:

Mesmo com 25 anos (na carreira) eu ainda não tenho aquela escola para chamar de minha, é ali que eu tenho o meu projeto, eu vou dar sequência, as turmas que eu trabalhei esse ano eu vou pegar elas o ano que vem. Eu não tenho nenhuma turma este ano que eu dei aula ano passado, são todas turmas novas (P9).

Da mesma forma, a itinerância afeta a organização do trabaIho pedagógico na Educação Física escolar, visto que a organização do trabalho docente ocorre de forma individualizada. Essas evidências aparecem no estudo, conforme os relatos a seguir:

Cada professor faz o seu. Cada professor está desenvolvendo da maneira que ele consegue desenvolver dentro da realidade e dentro do grupo de alunos que ele tem [...] (P2);

Eu acho que é muito individualizada. A gente não se reúne para fazer um planejamento só, cada professor faz o que quer [...] (P7).

Portanto, há a necessidade de se repensar a composição de um plano de carreira docente que viabilize a vínculo efetivo do professor predominantemente com uma instituição de ensino e sua permanência, uma vez que as condições de itinerância que estão dadas, podem levar à acentuação do quadro de precarização do trabalho docente (SAMPAIO; MARIN, 2004), com impacto nas políticas de formação continuada e na redução da atratividade da docência, como destacam Gatti e Barreto (2009).

\section{Intensificação do trabalho docente}

A reflexão sobre a intensificação e a consequente precarização do trabalho docente é fundamental, pois não é possível buscar o entendimento do mundo da educação e da escola desvinculado da vida social e das profundas transformações que configuram as novas feições do mundo do trabalho. No que tange à função docente, na sobrecarga de trabalho, está implícita a intencionalidade de aumentar o controle sobre o exercício da atividade do docente (VIEIRA, 2019).

Esta constatação, reflete diretamente com as constantes reestruturações no mundo do trabalho que alteram de maneira significativa as relações trabalhistas, marcada na sociedade capitalista contemporânea pela subproletarização (ANTUNES, 2015), além de outras formas de precarização laboral, como a intensificação do trabalho temporário, o subcontratado, o contrato por tempo parcial, a contratação por meio de empresas terceirizadas (PINTO, 2010).

Como nova dinâmica do desenvolvimento do capitalismo, a precarização do trabalho é elemento central, criando uma nova condição de vulnerabilidade social, um processo que modifica as condições de trabalho (assalariado e estável), anteriormente hegemônicas no período da chamada sociedade salarial ou fordista, para o modelo flexível ou toyotista. Nessa esteira, a flexibilidade se fez notar também nas contratações dos trabalhadores docentes. Na combinação de formas mais flexíveis entre a gestão do ensino e a regulação do trabalho, os docentes foram afetados por relações cada vez mais precárias e fragmentadas, que interferem em suas manifestações críticas e autônomas, contribuindo para um posicionamento de apenas adaptar-se às modificações e assim conseguir o trabalho, permanecendo desta forma por muitos anos sem estabilidade e sem local de trabaIho fixo. Sem escola para "chamar de sua", alternando turmas, turnos, sem possibilidade de dar continuidade no seu trabalho docente, para muitos professores, o recomeço pode ser mensal, semestral ou anual. Porém é certo que a sua condição de trabaIho será instável e flexível (DRUCK, 2011).

Uma das facetas a ser considerada na precarização do trabalho do profissional da educação é a carga horária excessiva de trabalho e de ensino com os alunos. Tal precarização, é re- 
tratada nas análises dos dados destacados pelos sujeitos, como ressaltam:

[...] basicamente, assim, trabalha as 40 horas semanais, entre elas horas atividades, horas em sala de regência, e depois nós temos outros projetos, esses projetos são desenvolvidos nos contraturnos, geralmente no final do dia [...]. Você trabalha sempre a mais daquilo que você tem na sua carga horária [...] (P1);

[...] é uma jornada bem cansativa, porque eu estou 40 horas, então assim, eu tenho meu tempo praticamente lotado" (P5).

A sobrecarga de trabalho impossibilita de realizar todas as tarefas no ambiente escolar, a diminuição da hora atividade e o aumento das exigências contribuem muito para este processo e, para compensar, o professor acaba trabalhando muito mais do que efetivamente recebe. Essas evidências podem ser observadas em seus relatos:

[...] é muito desgastante para nós querer fazer toda a proposta da escola, é muita coisa, porque o governo estadual, ele vem com muitas cobranças em cima do profissional com relação à avaliação [...]. A gente não consegue participar de tudo [...] (P2);

É a questão de levar as tarefas, os trabalhos, os planejamentos para fazer em casa, mas com a diminuição da hora atividade isso prejudicou bastante (P6)

Os diversos desafios da profissão docente, estão relacionados ao desenvolvimento histórico e à valorização social dessa profissão. No entanto, o contínuo acirramento da problemáti$\mathrm{ca}$, tem gerado ao docente, um profundo desgaste ante as insatisfações e descontentamentos dos alunos, a má qualidade do ensino, a desconfiança no aproveitamento social, além de elementos ligados à aprendizagem e suas perturbações (SANTOS, MOSQUERA e STOBÄUS, 2007). Segundo Both (2011), a sobrecarga de trabalho, juntamente com as obrigações familiares, interfere no modo que os professores encaram os fatores estressantes, pois, acabam afetando o nível de integração do professor em seu ambiente de trabalho, trazendo problemas patológicos, como consequência.

Outro fator preponderante para intensificação do trabalho docente é a quantidade de alunos que os professores precisam atender em cada classe e é uma das facetas que está diretamente ligada às condições de trabalho. A média aproximada de alunos por turma em que os docentes analisados na amostra trabalham é de 32 alunos, como apontam os dados apresentados anteriormente. Fica evidente nas manifestações dos sujeitos, que o elevado número de alunos por turma, afeta de forma negativa o trabalho docente e gera desgaste pessoal e profissional, como destacam:

Tem uma hora que a gente precisa ter o contato mais direto com o aluno e, é humanamente impossível com 30 alunos você conseguir atendê-los todos em uma aula [...] (P5);

O desgaste de uma aula com turma de 40 alunos é muito superior ao desgaste com uma turma de 20 alunos. Você precisa de muito mais energia, mais planejamento, mais organização para manter aquela turma interessada [...] isso gera estafa, sobrecarga no emocional, no físico e no mental (P9).

Esse contexto é uma das facetas relacionada às condições de trabalho. No Brasil, verifica-se uma queixa constante dos professores quanto a esse aspecto, pois na reorganização das escolas da rede pública, houve situações de algumas formarem turmas excessivamente numerosas, contando com a evasão de alunos para atingir uma composição numérica mais equilibrada (SAMPAIO; MARIN, 2004).

Ao serem questionados sobre as relações com os alunos, a indisciplina aparece como elemento de intensificação do trabalho, aliado ao desinteresse pela aprendizagem dos conteúdos abordados durante as aulas:

Com gritaria a gente acaba ficando sem voz, a minha voz já está assim, porque tem aqueles alunos que não ficam quietos para você explicar a atividade, isso atrapalha muito (P7);

[...] quando eles estão muito conversadores, atrapalha muito, porque você tenta explicar e tem uns 5 ou 6 alunos lá que conversam mais, você chama a atenção várias vezes, isso desgasta (P8).

A indisciplina dos alunos é fonte de várias pesquisas e tem sido um elemento desafiador para os educadores (JESUS, 1998; VIEIRA et al., 2016), pois é fator que contribui para o mal-estar docente e convergem para a ideia de professores desestimulados, o que prejudica a formação de um vínculo com a sua profissão e pode resultar em frustração, baixa autoestima e mal-estar docente (VIEIRA et al., 2016). Embora ainda seja um conceito amplo, que se torna difícil encontrar um consenso entre professores, quando se diz respeito aos comportamentos, há que considerá-la como variável relativa e subjetiva, dependendo muito da forma de atuação e do modo de como o professor vê a situação. De qualquer modo, é uma demanda acrescida e tem sido mais um desafio aos professores de Educação Física.

\section{CONCLUSÃO}

Diante do objetivo proposto e a partir dos achados no estudo, percebe-se a existência de motivação e empenho para o trabalho docente. No entanto, alguns entraves como a burocratização, o gerencialismo e o controle da atividade docente, incidem diretamente sobre suas condições de trabalho, que por consequência, repercutem na própria motivação e desenvolvimento profissional. Por outro lado, as condições no trabaIho dos professores de Educação Física, levantadas no estudo, evidenciaram situações contextuais que incidem e limitam o exercício do trabalho docente e geram consequências para sua condição de bem-estar, como o sentimento de desvalorização, desânimo, medo, preocupação com a profissão e insegurança quanto ao futuro na carreira.

A ocorrência da itinerância destaca-se como evento corrente e influenciador de uma rotina que intensifica o trabalho, pelo constante trânsito entre escolas, interfere no modo com que os professores enfrentam suas demandas de cada instituição, gera estresse excessivo, cansaço, afeta o nível de integração do professor com seu ambiente de trabalho e o equilíbrio entre vida pessoal e profissional. Tais circunstâncias levantadas, acentuam um quadro de precarização do trabalho docente, com potencialidade para impactar em sua própria motivação à docência e bem-estar.

Embora o objetivo do estudo tenha centrado no fenômeno da itinerância de professores de Educação Física, suas implicações para o processo de intensificação, precarização do trabalho docente e consequências na sua motivação e bem-estar, é fundamental que futuras investigações avaliem outros contextos, focalizem estudos sobre variáveis de saúde docente e acompa- 
nhem trajetórias de professores de Educação Física em sentido continuado.

Por fim, é importante destacar que o estudo foi restrito a uma amostra regional, e que as mudanças sociais no sistema educacional mencionadas, são talvez de significados diferentes em outras localidades, não sendo todos eles capturados nas entrevistas. Assim, os resultados de percepções individuais devem ser zelados para não causar induções gerais.

\section{REFERÊNCIAS}

ABONIZIO, G. Precarização do trabalho docente: apontamentos a partir de uma análise bibliográfica. Ensino de Sociologia em Debate, Londrina, v. 1, n.1, p. 1-28, 2012.

ANDRÉ, M. E. D. A. Estudo de caso em pesquisa e em avaliação educacional. Brasília: Líber, 2005.

ANTUNES, R. Os sentidos do trabalho: ensaio sobre a afirmação e negação do trabalho. São Paulo: Boitempo, 2015.

AZEVEDO, J. L. A educação como política pública. 3. ed. Campinas: Autores Associados, 2004.

BALL, S.; BAILEY, P.; MENA, P.; DEL MONTE, P.; SANTORI, D.; TSENG, C.; YOUNG, H.; OLMEDO, A. A constituição da subjetividade docente no Brasil: um contexto global. Educação em Questão, Natal, v. 46, n. 32, p. 9-36, 2013.

BARDIN, L. Análise de conteúdo. São Paulo: Edições 70, 2011.

BELL-RODRIGUES, R. F. Comprensión del ciclo para la inclusión educativa en la educación superior ecuatoriana. Revista Electrónica Educare, Heredia, v. 24 , n. 1 , p. $70-90,2020$

BOING, L. A. Os sentidos do trabalho de professores itinerantes. 2008. 191f. Tese (Doutorado em Educação) - Pontifícia Universidade Católica do Rio de Janeiro, Rio de Janeiro, 2008.

BOTH, J.; NASCIMENTO, J. V. Condições de vida do trabalhador docente em educação física do magistério público municipal de Florianópolis. Caderno de Educação Física e Esporte, Marechal Cândido Rondon, v. 9, n. 16, p. 1128,2010

DAVOGLIO, T. R.; SPAGNOLO, C.; SANTOS, B. S. Motivação para a permanência na profissão: a percepção dos docentes universitários. Psicologia Escolar e Educacional, São Paulo, v. 21, n. 2, p. 175-82, 2017.

DRUCK, G. Trabalho, precarização e resistências: novos e velhos desafios? Caderno CRH, Salvador, v. 24, n. 1, p. 37-57, 2011

FLORES, M. A. Tendências e tensões no trabalho docente: reflexões a partir da voz dos professores. Perspectiva, Florianópolis, v. 29, n. 1, 161-191, 2011.

FONTES, V. Capitalismo em tempos de uberização: do emprego ao trabalho. Marx e o Marxismo, Rio de Janeiro, v. 5, n. 8, p. 1-23, 2017

GATTI, B. A.; BARRETO, E. S. de S. Professores do Brasil: impasses e desafios. Brasília: UNESCO, 2009.

GUIMARÃES, A. I. R. A Transversalidade da motivação na docência. 2013. 119f. Dissertação (Mestrado em Educação) - Escola Superior de Educação de Paula Franssinetti, Porto, 2013.

KRAWCZYK, N. R.; VIEIRA, V. L. Homogeneidade e heterogeneidade nos sistemas educacionais: Argentina, Brasil, Chile e México. Cadernos de Pesquisa, São Paulo, v. 36, n. 129, p. 673-704, 2006

KRUG, H. N. A precarização do trabalho docente em educação física na educação básica. Gestão Universitária, Belo Horizonte, v. 8, n. 1, p. 1-12, 2017.

KRUG, N.; KRUG, R. R.; CONCEIÇÃO, V. J. S. Dar voz aos professores de educação física: as histórias de vida sobre os momentos significativos em relação as fases da carreira docente. Interfaces da Educação, Paranaíba, v. 4, n. 10, p. 109-33, 2013.

MARCONI, M. A.; LAKATOS, E. M. Fundamentos de metodologia científica. 6. ed. São Paulo: Atlas, 2005.

MAROSTICA, D.; SAMPAIO, A. A. Estresse em professores de educação física: potenciais causas e estratégias de enfrentamento. Caderno de Educação Física e Esporte, Marechal Cândido Rondon, v. 13, n. 2, p. 45-60, 2015.

MILANI, N. Z.; FIOD, E. G. M. Precarização do trabalho docente nas escolas públicas do Paraná. Roteiro, Joaçaba, v. 33, n. 1, p. 77-100, 2008.

NASCIMENTO, R. K.; BOTH, J.; GUIMARÃES, J. R. S.; BENITES, C. L.; FOLLE, A Perfis de satisfação no trabalho: um estudo com professores de educação física. Retos, San Javier, n. 42, p. 220-27, 2021.

OLIVEIRA, D. A. A Reestruturação do trabalho docente: precarização e flexibilização. Educação e Sociedade, Campinas, v. 25, n. 89, p. 1127-44, 2004.

PELOSI, M. B.; NUNES, L. R. O. Caracterização dos professores itinerantes, suas ações na área de tecnologia assistiva e seu papel como agente de inclusão escolar. Revista Brasileira de Educalção Especial, Marília, v. 15, n. 1 p. 141-54, 2009

PEREZ GOMEZ, A. A cultura escolar na sociedade neoliberal. Porto Alegre: Artemed, 2001.

PINTO, G. A. A organização do trabalho no século 20: taylorismo, fordismo e toyotismo. 2. ed. São Paulo: Expressão Popular, 2010.

PINTO, S. G.; ROSADO, D. G. Motivação docente: reflexões acerca de sua importância no processo de ensino-aprendizagem. FIEP Bulletin On-line, Foz do Iguaçu, v. 82, Edição Especial, p. 1-7, 2012.

QUADROS, L. R.; JUNIOR, S. de O.; CONCEIÇÃO, V. J. S.; WITTIZORECKI, E. S $\mathrm{O}$ trabalho docente de professores de Educação Física iniciantes na carreira: um estudo na região sul de Santa Catarina. Biomotriz, Cruz Alta, v. 12, n. 2 p. 259-72, 2018

RUFINO, L. G. B.; BENITES, L. C.; SOUZA NETO, S. Os desafios para o desenvolvimento do trabalho docente na perspectiva de professores de educação física. Corpoconsciência, Cuiabá, v. 21, n. 3 p. 55-65, 2017.

SAMPAIO, A. A.; STOBAUS, C. D. O apoio pedagógico na formação inicial: perspectivas para o bem-estar docente e desenvolvimento profissional. Espaço Pedagógico, Passo Fundo, v. 22, n. 2, p. 371-91, 2015

SAMPAIO, M. das M. F; MARIN, A. J. Precarização do trabalho docente e seus efeitos sobre as práticas curriculares. Educação e Sociedade, Campinas, v. 25, n. 89, p. 1203-25, 2004

SEKI, A. K.; SOUZA, A. G.; GOMES, F. A.; EVANGELISTA, O. Professor temporário: um passageiro permanente na educação básica brasileira. Práxis Educativa, Ponta Grossa, v. 12, n. 3, p. 942-59, 2017.

SHIROMA, E. O.; MORAES, M. C. M.; EVANGELISTA, O. Política educacional. 4. ed. Rio de Janeiro: Lamparina, 2011.

SILVA, O. O. N.; SOUZA, G. A. MIRANDA, T. G. BORDAS, M. A. G. B. O trabalho do professor de educação especial itinerante: Uma revisão sistemática. Educação, Psicologia e Interfaces, Ponta Porã, v. 4, n. 2, p. 51-66, 2020.

SILVA, M. R.; ABREU, C. B. M. Reformas pra quê? As políticas educacionais nos anos de 1990, o "novo projeto de formação" e os resultados das avaliações nacionais. Perspectiva, Florianópolis, v. 26, n. 2, p. 523-50, 2008.

SILVA, R. A. O.; GUILLO, L. A. Condições de trabalho e estresse: um estudo com professores da Educação Básica. Trabalho e Educação, Belo Horizonte, v. 24 , p. $153-66,2015$

SILVA, R. A. O.; GUILLO, L. A. Trabalho docente e saúde: um estudo com professores da educação básica do sudeste goiano. Revista Itinerarius Reflectionis, Jataí, v. 11, n. 2, p. 1-17, 2015

STOBÄUS, C. D.; MOSQUERA, J. J. M.; SANTOS, B. S. Grupo de Pesquisa mal-estar e bem-estar na docência. Educação, Porto Alegre, v. 30, n. especial, p. 259-72, 2007

VENTORIM, S.; ASTORI, F, B, da S.; BITENCOURT, J. F. O desmonte das políticas de formação de professores confrontado pelas entidades acadêmico-científicas. Jornal de Políticas Educacionais, Curitiba, v. 14, n. 22, p. 1-20, 2020.

VIEIRA, J. S.; GONÇALVES, V. B.; MARTINS, M. F. D. Trabalho docente e saúde das professoras de educação infantil de Pelotas, Rio Grande do Sul. TrabaIho, Educação e Saúde, Rio de Janeiro, v. 14, n. 2, p. 559-74, 2016.

WITTIZORECKI, E. S. Mudanças sociais e o trabalho docente do professorado de educação física na escola de ensino fundamental: um estudo na rede municipal de ensino de Porto Alegre. 2009. 227f. Tese (Doutorado em Ciências do Movimento Humano) - Universidade Federal do Rio Grande do Sul, Porto Alegre, 2009.

WITTIZORECKI, E. S.; MOLINA NETO, V.; BOSSLE, F. Mudanças sociais e o trabalho docente de professores de Educação Física na escola: estudo a partir de histórias de vida. Movimento, Porto Alegre, v. 18, n. 1, p. 149-69, 2012. 


\section{AGRADECIMENTOS}

Os autores agradecem aos professores da Secretaria de Estado de Educação (SEED-PR), participantes do estudo.

\section{CONFLITO DE INTERESSE}

Os autores do estudo declaram não haver conflito de interesses.

\section{FINANCIAMENTO}

Este estudo não teve apoio financeiro.

\section{ORCID E E-MAIL DOS AUTORES}

Susana Hahn

ORCID: 0000-0003-3922-8355.

E-mail: susana96_hh@hotmail.com

Arestides Pereira da Silva Junior

ORCID: 0000-0003-0647-1930.

E-mail: arestidesjunior2000@yahoo.com.br

Carlos Seibert

ORCID: 0000-0003-0093-7437.

E-mail: carlosseibert@yahoo.com.br

Dartel Ferrari de Lima

ORCID: 0000-0002-3633-9458.

E-mail: dartelferrari07@gmail.com

Jorge Both

ORCID: 0000-0002-8238-5682.

E-mail: jorgeboth@yahoo.com.br

Oldemar Mazzardo

ORCID: 0000-0001-5325-9815.

E-mail: oldemar.junior@unioeste.br

Adelar Aparecido Sampaio (Autor Correspondente)

ORCID: 0000-0003-4386-1364.

E-mail: adelarsampaio@hotmail.com 